\title{
Synthesis and Biological Evaluation of 1-(5-((9H-Carbazol-9-yl) Methyl)-2- Methyl-1,3,4-0xadiazol-3(2H)-yl)Ethanone
}

\author{
S Muralikrishna* \\ Biological E.Ltd Company, shameerpet, India \\ Received: April 28, 2018; Published: May 08, 2018 \\ *Corresponding author: S Muralikrishna, Biological E.Ltd company, shameerpet, Hyderabad, India
}

\begin{abstract}
SYNTHESIS AND BIOLOGICAL EVALUATION OF 1-(5-((9H-carbazol-9-yl)methyl)-2-methyl-1,3,4-oxadiazol-3(2H)-yl)ethanonering were synthesized by the condensation of 2-(9H-carbazol-9-yl)acetohydrazide with 2-(9H-carbazol-9-yl)- $\mathrm{N}^{\prime}$-ethylideneacetohydrazide and acetic anhydride. To this reaction was subjected. It forms 2-(1-((4-acetyl-5-methyl-5-(trifluoromthyl)-4,5-dihyro-1,3,4-oxadiazol-2-yl)methyl)-1Hindol -3yl)-3-(p-tolyl)thiazolidin-4-one.The structure of these newly synthesized compounds were characterised by $1 \mathrm{H}$ NMR,13CNMR ,Mass ,IR, and elemental analysis.
\end{abstract}

Keywords: 1, 3, 4oxadiazole; Acetic Anhydride; Carboxazole

\section{Introduction}

Hetero cyclic compounds represents an important class of biological molecules.The hetero cyclic molecules which, posses indole,1,3,4oxadiazole moieties exhibit wide range of biological activities. carbazoles are one of the most important alkaloids molecules found extensively in biological systems, which play vital role in many of the biochemical process. carbazoles ring constitutes an important basic Skelton and development of the drug.The classical indole drugs are found to posses high which includes, antibacterial, analgesic, antipyretic, antifungal, antiflamatory, anthelmintic, cardiovascular, anticonvalsant and selective COX-2 inhibitary activities. 1,3,4-oxadizoles has become an important synthon for the development new therapeutic agents. Compounds with 1,3,4-oxadiazole core substantiate for broad spectrum of biological activities including antimicrobial [1], antifungal [2], antiinflammatory [3], anticonvulsant [4], antioxidant, analgesic [5] and mutagenic activity [6]. Compounds containing quinoline moiety are most widely usedas antimalarials [7], antibacterials [8], antifungals [9], anticancer agents [10] and potential HIV-1 integrase inhibitors [11-12].

Hetero cyclic compounds represents an important class of biological molecules.The hetero cyclic molecules which, posses indole,1,3,4oxadiazole and thiazolidinone moieties exhibit wide range of biological activities. Indoles are one of the most important alkaloids molecules found extensively in biological systems, which play vital role in many of the biochemical process. Indole ring con stitutes an important basic skelton and development of the drug. The classical indole drugs are indomethacin and indoxole. Indole derivetives found to posses high which includes,antibacterial,analgesic,antipyretic,antifungal,antiflamatory,anthelmintic,cardiovascular,anticonvalsant and selective COX-2 inhibitary activities. 1,3,4-oxadizoles has become an important synthon for the development new therapeutic agents. Compounds with 1,3,4-oxadiazole core substantiate for broad spectrum of biological activities including antimicrobial [1], antifungal [2], anti-inflammatory [3], anticonvulsant [4], antioxidant, analgesic [5] and mutagenic activity [6]. Compounds containing quinoline moiety are most widely usedas antimalarials [7], antibacterials [8], antifungals [9], anticancer agents [10] and potential HIV-1 integrase inhibitors [11-12].

Synthesis of 2-(9H-Carbazol-9-yl)-N'-Ethylideneacetohydrazide(3)

To the solution of 2 (a) $(0.01 \mathrm{~mole})$ in hot methanol $(25 \mathrm{ml})$, acetophenone(0.01) and a drop of glacialacetic acid were added. The solid that seperated on refluxing for 3 hours was filtered wash with cold methanol and recrystalised from methanol to give 7(a).M.P.2360C,yield 84\%.

$$
\begin{aligned}
& \text { IR (KBr) vmax (cm-1): } \\
& 3418.21(\mathrm{~N}-\mathrm{H}), 2360.4-2922.59(\mathrm{Ar}-\mathrm{H}) ; 1 \mathrm{H} \text { NMR }
\end{aligned}
$$




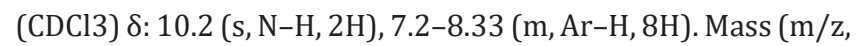
$\%)$ : 167.8 ; Anal. calcd. for

C, 86.20; H, 5.43; N, 8.38\%; Found: C, 86.21; H, 5.42; N, 8.37\%.

Synthesis and Biological Evaluation of 1-(5-( (9H-Carbazol-9-yl)Methyl)-2-Methyl-1,3,4-0xadiazol-3(2H)-yl) Ethanone(4)

A mixture of carbazole derivatives and acetic anhydride(5) $(0.01 \mathrm{~mol})$

was heated at 100-120 oC in presence of excess is added. After cooling, the mixture was poured into crushed ice, and neutralized with $5 \%$ aq.NaHCO3 solution. The precipitated solid was filtered and purified using column chromatography (petroleum ether:ethyl acetate, 9:1).

Yield: 60\%: mp 190.7 •C. IR (KBr) cm-1: v $3150(\mathrm{~N}-\mathrm{H}), 3050-$ 2750 (C-H). 1H-NMR

(CDCl3): $\delta, 7.65(\mathrm{~d}, 1 \mathrm{H}, 1 \mathrm{H}$-indazole H4, J = 7.6), $7.35(\mathrm{~d}, 1 \mathrm{H}$, indole H7, J = 8),6.80-

$6.85(\mathrm{~m}, 3 \mathrm{H}$, indole H2, H5, H6), 7.35-7.45(m,5H,phenyl group),3.80 (s, 2H, C-CH2 -N),

$3.25(\mathrm{t}, 4 \mathrm{H}$, piperazine $\mathrm{H} 3, \mathrm{H} 5, \mathrm{~J}=4.8), 2.70(\mathrm{t}, 4 \mathrm{H}$, piperazine H2, H6, J = 4.8),, Anal.

Calc. for: C, 78.32; H, 7.26; N, 14.42\%, found:C, 78.18; H, 6.94; $\mathrm{N}, 14.25 \%$,

\section{Anti-Bacterial Activity}

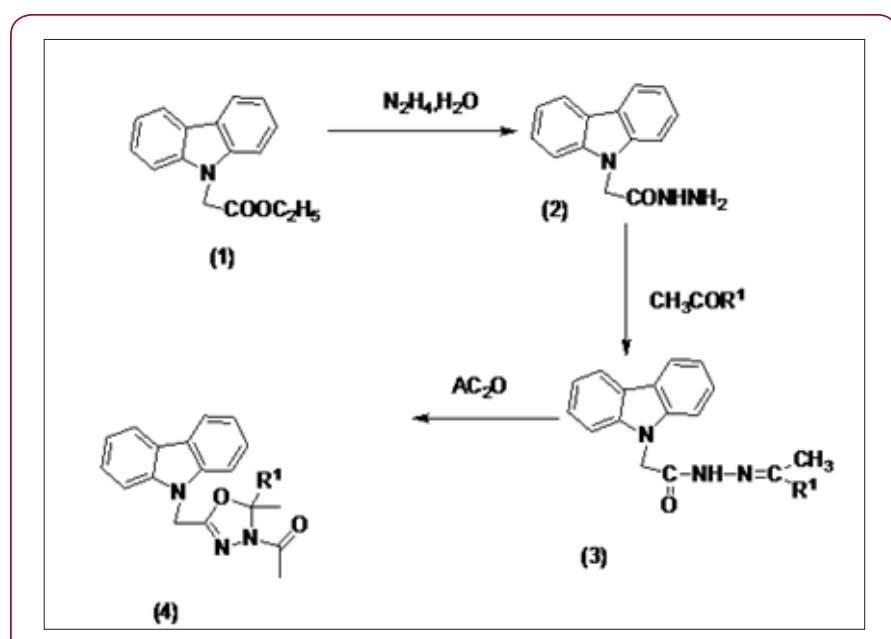

Figure 1.

The anti-bacterial activity of synthesized compounds was studied by the disc diffusion method against the following pathogenic organisms. The gram-positive bacteria screened were staphylococcus aureus NCCS 2079. The gram negative bacteria screened were Escherichia coli NCCS 2065 and pseudomonas aeruginosa NCCS 2200. The synthesized compounds were used at the concentration of $250 \mu \mathrm{glml}$ and $500 \mu \mathrm{glml}$ using DMSO as a solvent the Cefaclor $10 \mu \mathrm{glml}$ disc was used as a standard. (Himedia,Laboratories Ltd, Mumbai).The test results presented in the Table 1 and (Figure 1) suggest that $4 \mathrm{~b}, 4 \mathrm{~d}, 4 \mathrm{e}$ exhibit high activity against the tesed bacteria, the rest of the compounds were found to be moderate active against the tested microorganisms [13-14].

Table 1.

\begin{tabular}{|c|c|c|c|c|c|c|}
\hline COMPOUND & $\mathbf{4 ( a )}$ & $\mathbf{4 ( a )}$ & $\mathbf{4 ( a )}$ & $\mathbf{4 ( a )}$ & $\mathbf{4 ( a )}$ & $\mathbf{4 ( a )}$ \\
\hline $\mathrm{R}^{1}$ & $\mathrm{H}$ & $\mathrm{CH}_{3}$ & $\mathrm{OCH}_{3}$ & $\mathrm{Cl}$ & $\mathrm{NO}_{2}$ & $\mathrm{CF}_{3}$ \\
\hline
\end{tabular}

\section{Antifungal activity}

The antifungal activity of synthesized compounds were studied by disc diffusion method against the organisms of Penicillium and Trichophton. Compounds were treatd at the concentrations of $500 \mu \mathrm{glm}$ and $1000 \mu \mathrm{glml}$ using DMSO as solvent. The standard used was Clotrimazole $50 \mu \mathrm{glml}$ against both organisms.

\section{References}

1. Rakesh R Somani, Anuj G Agrawal, Pushkar P Kalantri, Pratibha S Gavarkar, Erik De Clerq (2011) International Journal of Drug Design and Discovery 2(1): 353-360.

2. Ponnilavarasan Ilangovan, Ayaluraja Sekaran, Sundaramoorthi, Chenniappan, Bhalchandra Keshao Chaple (2011) Journal of Pharmacy Research 4(6): 1696-1698.

3. Rakesh Saini, Saurabh Chaturvedi, Achyut Narayan Kesari, Swatrantra Kushwaha,DerPharma

Chemica (2010) 2(2): 297-302.

4. Mohd Amir, SA Javed and Harish Kumar (2007) Indian Journal of Chemistry 46B: 1014-1019.

5. Poonam Singh, Pankaj K Jangra (2010) Oxadiazoles: A novel class of anticonvulsant agents. Der ChemicaSinica 1 (3): 118-123.

6. M Vijey Aanandhi, Mohammed Hashim Mansoori, S Shanmugapriya, Shiny George, PShanmugasundaram (2009) Research Journal of Pharmaceutical, Biological and Chemical Sciences 59: 223-233.

7. A Bilker O, Lindo V, Panico M, Etiene AE, Paxton T, et al. (1998) Nature 392: 289-292.

8. Winstanley PAToday (2000) 16: 146-153.

9. Chevalier J, Atifi S, Eyraud A, Mahamoud A, Barbe J, et al. (2001) New Pyridoquinoline Derivatives as Potential Inhibitors of the Fluoroquinolone Efflux Pump in Resistant Enterobacter aerogenes Strains. J Med Chem 44: 4023-4026.

10. Majerz-Maniecka K, Oleksyn B, Musiol R, Podeszwa B, Polanski J (2005) Potential Vienna, Austria In Sci Pharm 73(Suppl. 1): 194.

11. Vargas LY, Castelli MV, Kouznetsov VV, Urbina JM, Lopez SN, et al. (2003) In vitro antifungal activity of new series of homoally lamines and related compounds with inhibitory properties of the synthesis of fungal cell wall polymers Bioorg Med Chem 11: 1531-1550.

12. Bailly C, Laine W, Baldeyrou B, De Pauw-Gillet MC, Colson P, et al. (2000) Anti-Cancer Drug Des 15: 191-201.

13. Polanski J, Niedbala H, Musiol R, Podeszwa B, Tabak D, et al. (2006) Lett Drugs Des Disc 3: 175-178.

14. Polanski J, Niedbala H, Musiol R, Podeszwa B, Tabak D, et al. (2007)Drugs Des Disc IntegraseInhibition 4: 99-105. 
(c) (1) This work is licensed under Creative

Submission Link: https://biomedres.us/submit-manuscript.php

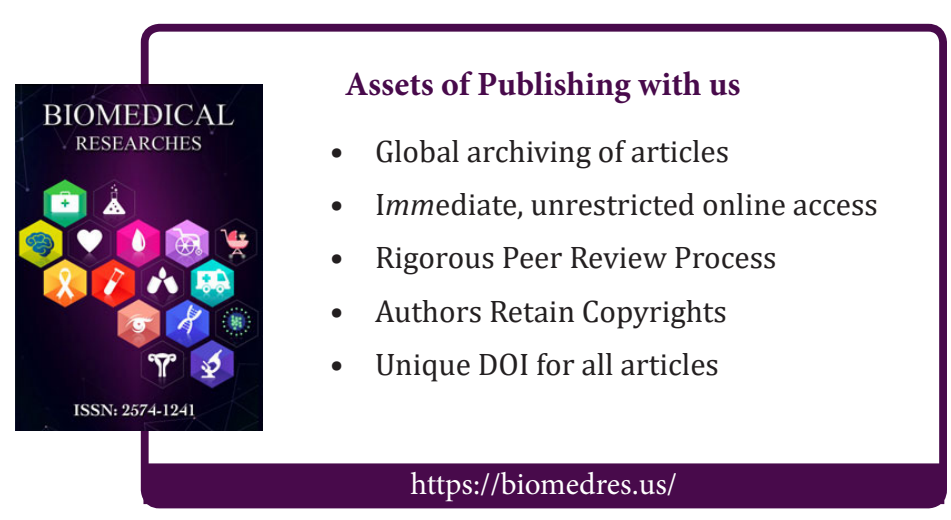

